\section{A Study on the Ability of Supra- Segmental and Segmental Aspects in English Pronunciation}

\author{
1. Febronia Lasi \\ 1 Universitas Timor, Indonesia
}

\begin{abstract}
This study attempted to examine the EFL students' Basic English Pronunciation (BEP) at the first semester of the English study program, the State University of Timor. It was aimed at finding out the mastery of the students' ability towards the Basic English Pronunciation (BEP), to what extent do the students still find difficulties to pronounce the basic English words, and to what level do the students' mastery level of pronunciation categorized? The method applied in this research was a descriptive quantitative method that employed the syntax of mathematical operation to investigate the properties of data collection (Walliman, 2005). The instrument was a list of 24 numbers of groups of Voice Consonants and Unvoiced Consonants of Basic English Pronunciation taken from "Improve Your English Pronunciation and Learn over 500 Commonly Mispronounced Words", meanwhile, 26 students were chosen from the freshmen students of English Study Program (ESP) to be the subject of this present study. The result showed that the students' ability in pronouncing the Basic English words was fair. Particularly, the students mostly had the 'Enough' level of ability at the four elements of supra-segmental as such: stress, intonation, voice quality and gesture. Specifically, at this 'Enough level', there were 16 students (61.5\%) of 'Stress' element, 17 students (65.3\%) of 'Intonation' element, 13 students (50.0\%) of 'Voice Quality' and 'Gestures' as part of Segmental element was 16 students (61.5\%). Meanwhile, at the 'Rhythm' element, most students $(53.8 \%=14$ students) showed the 'Less' ability in this element and only 12 (46.1\%) categorized at the level of "enough". Otherwise, there were no students in the 'Bad' level category. However, few students still encountered difficulties in Segmental element (Voice Quality) and Supra-segmental parts such as words' stressing, intonation, rhythm, and gestures respectively.
\end{abstract}

\section{Keywords}

Basic English pronunciation

Supra-segmental

Segmental

\section{Ethical Lingua}

Vol. 7, No. 2, 2020

ISSN 2355-3448 (Print)

ISSN 2540-9190 (Online)

Corresponding Email

Febronia Lasi

febry1202@gmail.com

Article's History

Submitted 5 October 2020

Revised 7 October 2020

Accepted 8 October 2020

DOI

10.30605/25409190.222

Copyright (๑) 2020

The Author(s)

This article is licensed under CC BY-NC-SA 4.0 License 


\section{A Study on the Ability of Supra-Segmental and Segmental Aspects in English Pronunciation}

Pronunciation is the process of producing comprehensible sound by articulating speech organs such as lips, teeth, lungs, vocal tracts and tongue. To pronounce words, we push air from our lungs up through our throat and vocal chords, through our mouth, past our tongue and out between our teeth and lips. To change the sound that we are making, we mainly use the muscles of our mouth, tongue and lips to control the shape of our mouth and the flow of air. This is why, English pronunciation is considered one of the most difficult skills to acquire and learners should spend lots of time to improve their pronunciation (Gilakjani, 2016). Understandable pronunciation is one of the basic requirements of learners' competence and it is also one of the most important features of language instruction. Good pronunciation leads to learning while bad pronunciation promotes to great difficulties in language teaching (Gilakjani, 2016)

Various researches have confirmed that the speakers of other languages who learn English tend to make mistakes. This case showed that they simply shift the pronunciation of, for example, consonants in English to the consonant sound in their native language that is close in pronunciation, e.g. they substitute $/ \mathrm{p} /$ with $/ \mathrm{b} /, / \theta /$ with $/ \mathrm{s} /$. etc (Donald Carter and David Nunan), 2001; O'Connor, 2009). Moreover, numbers of the studies related to mispronunciation have been conducted several times. Some of them are researches conducted by Habibi (2016), Luviya (2016), Hassan (2014), and Algifari (2017). First of all, Habibi (2016) examined segmental mispronunciations faced by advanced students of Maulana Malik Ibrahim State Islamic University of Malang. The segmental mispronunciations in the research referred to mispronunciations of vowels and consonants in English. In addition, the researcher chose the subjects of the research based on the criteria of advanced students stated by Cotter (cited in Habibi, 2016). Employing descriptive qualitative approach, the study found that the subjects encountered segmental pronunciation problems such as substitution

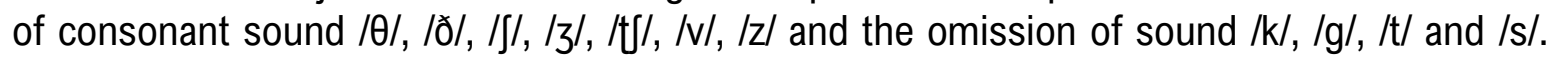
Vowel mispronunciations were also pointed out such as $/ \mathrm{i}: /, / \mathrm{I} /, / \varepsilon /$, /D/, /J/, / / /, / / /, /3:/ and monophthongisation of /ei/, /aI/, /as/, /rə/, etc.

Likewise, Indonesian students make mistakes as well by creating substituted sounds to the language they are familiar with. They have a tendency to commit replacement of the sound /v/ with /f/, / $\theta /$ with /t/, etc (Habibi, 2016). This is because, like Arabic-English case, does not necessarily have some of the sounds English has such as $/ \theta /(\mathrm{p} /$ sound in Arabic case). Although Indonesian has the letter / $/ \mathrm{in}$ its words, it is normally pronounced as / $/ \mathrm{f} /$. It is also worth mentioning that English pronunciation of consonant and vowel sounds as well as stressing syllable(s) at the correct and appropriate place.

Further, Hassan (2014) studied the same pronunciation problems encountered by the students of the University of Science and Technology in Sudan which Sudanese Spoken Arabic is their first language. It can be learnt from the results of the study that Sudanese students had problems in pronouncing $/ \mathrm{s} /$ and $/ \theta /, / \mathrm{z} /$ and $/ \delta /, / \mathrm{b} /$ and $/ \mathrm{p} /$, etc. It was also concluded that the factors that made these errors possible were due to diversities in the sound systems in two languages such as the inconsistency of English sound-spelling. 
Moreover, Anindita (2017) also directed a study focusing on English mispronunciation by Radio Masdha announcers in Yogyakarta. The study mentioned that the radio station always makes renewal for their announcer every academic year to give freshmen the chance to test out their English, meaning that they only select those who are capable. The result showed that the announcers examined made frequent mispronunciations in pronouncing $/ v /, / \delta /, / \theta /$, $|z|$, etc

Nonetheless, the prior studies have enlightened this research to fill in the gap among them. None of the studies mentioned combines more than one parts of pronunciation (i.e. combining segmental and supra-segmental features). Therefore, this present research aims and focuses to fill in the gap by focusing on the aspects of segmental and supra-segmental in English pronunciation.

As an integrated and integral part of language learning, Pronunciation consists of elements much wider than sounds of consonants and vowels. It includes the elements of rhythm and intonation, which support the communicative process. Anyone who wants to gain communicative competence has to study pronunciation. Pronunciation refers to the production of sounds that people use to make meaning. It includes attention to the particular sounds of a language (segments), aspects of speech beyond the level of the individual sounds, such as intonation, phrasing, stressing, timing, rhythm (supra-segmental aspects), how the voice is projected (voice quality), and in its broadest definition, attention to gestures and expression that are closely related to the way we speak a language. There are some basic sounds of English such as park, best, time, done, etc.

Many students have problems in learning English especially in spoken English language. They are mentioned as the following order: first, what student can hear; some students have great difficulty hearing pronunciation features which we want them to reproduce. Oftentimes, speakers of different first languages have problem with sounds. Second is what students can say; learning a foreign language often presents us with the problem of physical unfamiliarity, for example, it is actually physically difficult to make the sound using particular parts of the mouth, uvula or nasal cavity. The third is the intonation problems; some of us especially our students still find it extremely difficult to hear tunes or to identify the different patterns of rising and falling tones.

Further, the EFL students of English study program at Timor University also find difficulties and sometimes make mistakes in pronouncing the English words. Often times, they misunderstood the English words while listening to the audio listening or even in speaking. Moreover, this is not only found in listening and or in speaking skills but also in reading and writing.

This is predictable that it is caused by their first languages or mother tongues they speak. It has been seen from this short introduction that pronunciation is very important and that the students should pay more attention in pronunciation as early as possible. These circumstances make the author interested in analyzing the students' ability in pronouncing English words to know the ability on the basic EFL learners of English pronunciation to the first semester students of English Study Program, State University of Timor. There are three main problems of the research were stated as follows: (1) What are the ESP students' ability towards Basic English Pronunciation? (2) To what extend do the ESP students still find difficulties to pronounce the Basic English words? And (3) What are the level of the students' mastery in pronunciation? Based on the research problems mentioned above, this study was aimed at finding out the mastery of the students' ability towards Basic English Pronunciation 
(BEP), the students' difficulties in pronunciation related to supra-segmental and segmental elements in BEP, and the students' mastery categorized in BEP.

\section{Elements of Basic English pronunciation}

A broad definition of pronunciation includes both supra segmental and segmental features. Although these different aspects of pronunciation are treated in isolation here, it is important to remember that they all work in combination when we speak and are therefore usually best learned as an integral part of spoken language. Traditional approaches to pronunciation have often focused on segmental aspects, largely because these relate in some way to letters in writing, and are therefore the easiest to notice and work on. More recent approaches to pronunciation, however, have suggested that the supra segmental aspects of pronunciation may have the most effect on intelligibility for some speakers.

\section{Supra Segmental Aspects of Pronunciation}

\section{Stress}

Stress on both the word and the sentence levels is another significant feature of pronunciation. Underhill (2005: 51-54) defines word stress as "accent or emphasis given to a particular syllable of a word." The emphasis on the stressed syllable can be described as "louder, longer, and different in pitch." Words with two syllables always have one stressed and one unstressed syllable. Words with three and more syllables also have a secondary stress, which is less strong than the primary one. Hence, there are three levels of word stress: primary, secondary, and un-stress. Kelly and Kenworthy use very similar descriptions of word stress. Likewise, Kelly (2000: 70) divides languages according to word stress into two groups. The languages in which the span of a sentence is dependent on the number of stresses are called stress-timed. English is a typical example of such a language. The other groups of languages are called syllable-timed. The sentence span depends on the number of syllables. Furthermore, Kenworthy (1987: 28) emphasizes the importance of teaching word stress as well. He claims that it is as much important as teaching the individual sounds. A perfectly pronounced word with wrong stress might cause a native speaker a great problem in understanding. Yates (2002: 2) adds that teachers should focus on stress of every new word with more than one syllable. Sentence stress is another level of stress. Kenworthy (1987:32) explains that it is a way of giving significance to a particular word in an utterance. Yates (2002: 2) supports Kenworthy's explanation by claiming that "the most important words tend to be stressed."

All the authors above put a lot of emphasis on the role of stress when speaking English or within pronunciation itself. Nevertheless, none of them deals with the practical part of teaching stress. When introducing stress to the learners teachers have to decide what kind of presentation they will use. Stress can be labeled in many ways, but the most frequent mark is an apostrophe. Nevertheless, teachers can also utilize other labels, such as underlying the stressed syllable, using a different color, circles, hyphens, capital letters, and others. Teachers and their students just have to agree on the mark which will be convenient for both.

Every English multi-syllabic word has a syllable that receives the main stress. This is part of each word's signature, so to speak. But in the focus word, this stressed syllable gets special attention, because it represents the peak of information in the thought group. It is the most 
important syllable within the most important word, and therefore, the sounds in the peak syllable must be heard clearly (Gilbert, 2008).

Many teachers advocate starting with stress as the basic building block of pronunciation teaching. Stress refers to the prominence given to certain syllables within words, and to certain syllables or words within utterances. It is signaled by volume, force, pitches change and syllable length, and is often the place where we notice hand movements and other gestures when we are watching someone talking. One noticeable feature of English is the reduced nature of unstressed syllables. Thus, not only they are stressed syllables longer, louder, more forceful and at the different pitch, but unstressed ones are often different in quality. Stress is important at three different levels; 1) Word level- multisyllabic words have one or more syllables that are stressed, 2) Sentence level- the most important words tend to be stressed, and 3 ) Contrastive stress- the most important words carry greater stress.

\section{Intonation}

The term intonation refers to the way the voice goes up and down in pitch when we are speaking. It is a fundamental part of the way we express our own thoughts, and it enables to understand those of others. It is an aspect of language that we are very sensitive to, but mostly at an unconscious level. We perceive intonation, understand it and use it without having to examine the intricacies of everything we say or hear (Kelly, 2000:86). Additionally, Hewings (2004: 7-9) defines intonation as "the way the pitch of the voice falls or rises." He lists several reasons for using intonation. It shows whether the information is new or known in the conversation. It also divides the conversation into various segments and it also expresses the speaker's opinion, which is closely connected with gestures and facial expressions. Moreover, Underhill (2005: 74-5) characterizes intonation as "it's not what you say, but the way you say it." He also mentions that a choice of intonation can be subjective, which makes it rather difficult to teach. Another fact that could discourage teachers from employing intonation in the lesson is the absence of really practical rules of using intonation. Finally, teachers themselves are not self-confident in this field. It is believed that intonation is rather difficult to explain because it is not as practical as the other aspects of pronunciation.

From this, teaching intonation seems to be rather complicated. Nevertheless, teachers should not avoid it. It is advisable to incorporate intonation into other pronunciation aspects. It is also recommended to rely on students' inherent feeling to imitate what they hear. Thus, regular exposition to spoken English should help them follow the right intonation. As well as helping to determine meaning, intonation gives us clues about the attitude of the speaker, or how he/she feels about what he/she is saying. When listening to people speaking, we get clear messages about their attitude from the ways things are said. We can get a good idea, for example, as to whether someone is interested, bored, being kind being honest or lying, and so on.

Student difficulties with intonation are not helped by the fact that concentrations on grammar and vocabulary often take their attention away from this feature. Struggling to find the right words will mean that the smooth movement of intonation will be interrupted. In short, intonation needs to be a feature of classroom language analysis and practice. This will help students toward greater expressiveness and articulacy in English, and also help them to a better understanding of some the subtleties of native - speaker speech. 


\section{Rhythm}

Children learn the rhythm of their first language very early in life. Since English learners will be predisposed to use the rhythm of their first language, it is highly important that they be made consciously aware of the English system of rhythm (Gilbert, 2008). The basic unit of English rhythm is the syllable. A syllable is most simply explained as something whit a vowel sound at its center. And writer the number of syllable deviations in the same way. Since this seriously affects both intelligibility and listening comprehension, time must be spend training student ears to notice the number of syllables in the words they learn, for instance, students should be taught to count syllables and thereby notice the rhythmic difference between words in pairs, such as ease and easy, or wait and waited (Gilbert, 2008).

Underhill (2005: 176) defines rhythm as "the perception of some kind of underlying regularity of occurrence of prominences and word stresses." To teach pronunciation at a beginner's level he offers using authentic metrical texts, such as nursery rhymes. Following the rhythm of the rhymes, learners sound English very quickly (Underhill, 2005: 180). On the other hand, he adds that what is 'unteachable' is not 'unlearnable'. He even suggests beginning to teach pronunciation with these aspects because it is more natural. When teaching rhythm and intonation he recommends combining them with context and other aspects of pronunciation. Learners should start with receptive activities and listen to real materials.

All above authors consider the rhythm as much difficult to teach as intonation. Therefore, they give teachers very similar advice for both aspects. Anyway, despite being on the margins of pronunciation teaching, both rhythm and intonation deserve much attention of teachers and learners.

\section{Voice Quality}

Voice quality has received little attention in second language learn, although actors may be quite familiar with the concept. The term refers to the more general, longer-term articulator settings shared by many sounds within a language, and these affect accent and the quality of voice in global way. Basically, the argument is that areas of the mouth may be held ready in particular long term settings which affect the overall quality of the accent. Since different languages have different long-term settings, getting learners to focus the settings relevant to English may help the learner with individual sounds as well as their overall voice quality, particularly for first language speakers with settings that differ considerably from English.

\section{Segmental Aspects of Pronunciation}

Learning to pronounce the sounds of English in natural speech is a crucial part of learning pronunciation in English. Many learners may have difficulty with particular sounds, sounds combinations or with putting particular sounds in particular position. The sound system of English is made up of phonemes, or individual sounds which carry the potential to make meaning, and these may be vowels, diphthongs (combinations of two vowel sounds), tripthongs (combinations of three vowel sounds) or consonants. These sounds are made using our tongue in different parts of the mouth. Underhill (1994) gives a teacher-friendly description of the sounds of English, and provides a phonemic chart arranged according on how they are made in the mouth. These sounds are represented using a phonemic script, like that used in the front of dictionaries. It is very useful for teachers to become familiar with this 
script, and more details and examples of how it is used can be found in reference works such as Underhill (2005) and Roach (2009).

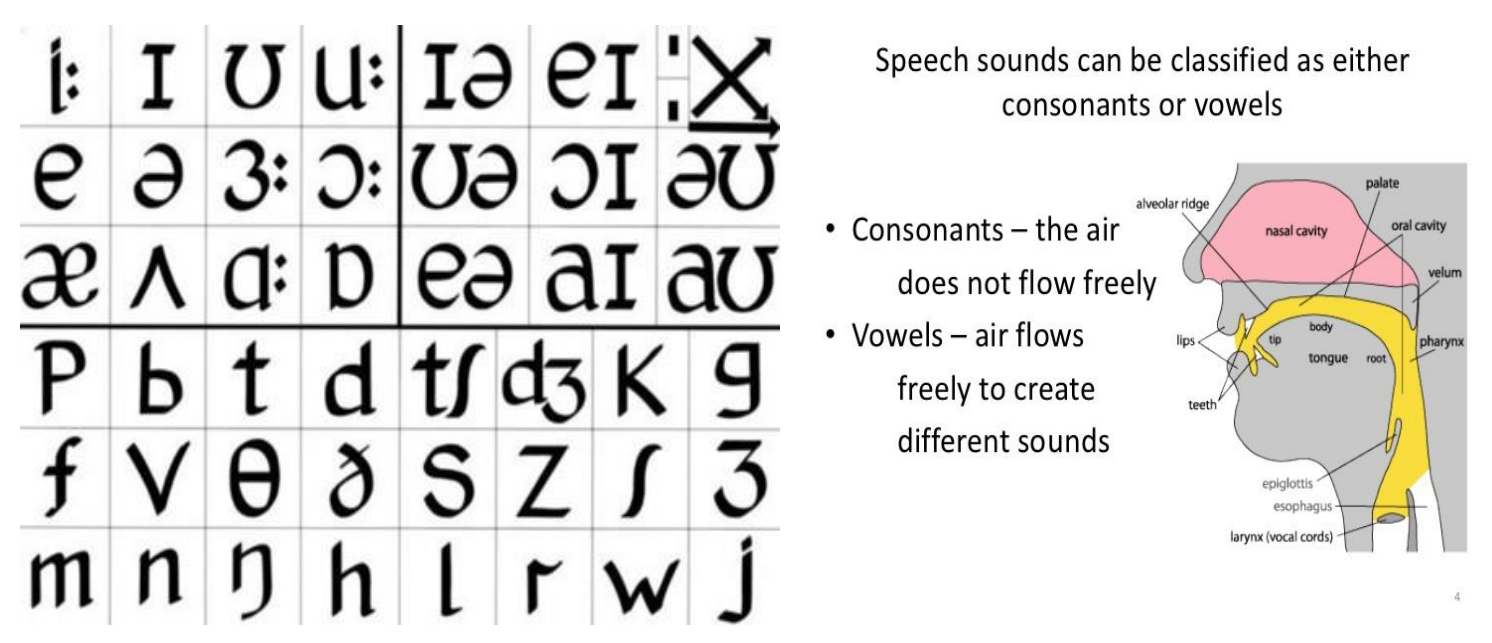

(Reprinted from Sound foundations 1994 by Adrian Underhill with kind permission of Macmillan Education, UK)

Consonant are made by causing a blockage or partial blockage in the mouth, and these are usually described in terms of: 1) where the sound is made in the mouth or place of articulation, 2) how the sound is made, or the manner of articulation, and 3) whether or not the vocal cords vibrate, or voicing. Consonants, therefore, all differ from each other in at least one of these ways. The consonants of English are shown in the following table, according to where and how they are made. (Adapted from Roach, 2009: 62)

\section{Gestures}

There has been quite a lot of interest in how the movements that our body makes as we are speaking may be closely related to how we speak, and some approaches to the teaching of pronunciation heavily emphasis training in gestures associated with speaking habits in English. As we speak, we synchronize many of our movement with the rhythm of what we are saying, so that focusing on the movements may help learners develop awareness of stress and rhythm.

\section{Method}

This study applied quantitative method which employed the syntax of mathematical operations to investigate the properties of the data (Walliman, 2005:302). The sample was selected from the number of cases in a population, the first semester students of English Study Program (ESP), State University of Timor-Indonesia was chosen randomly from three parallel classes to be the subject of this present study that consisted of 26 students $(\mathrm{N})$ and the aged ranged between 18 to 25 years old. Meanwhile, list of 100 Basic English vocabularies and a tape recorder were the instruments used to record the students' English pronunciation of the words listed in order to identify the students' voices.

In gathering the data there were two steps applied as such library and field researches. There was a 24 numbers of group of Voice Consonants and Unvoiced Consonants of Basic English Pronunciation taken from "Improve Your English Pronunciation and Learn over 500 Commonly Mispronounced Words" by Jakub Marian (http://jakubmarian.com/) and given to the students to read and speak it out while the researcher recorded the students' when they 
pronouncing the words. After they pronounced the listed words, the students were asked to write it down on the white board to check if they made mistakes or not. These data then analyzed using codification, categorization, tabulation, and discussion.

The criteria to give the score of basics English pronunciation in speaking based on 2 aspects of pronunciation. First, Supra-segmental consisted of 'Stress, Intonation, Rhythm, and Voice Quality', while the second one was Segmental encompassed 'Gesture'.

To analyze the data on the students' Basic English Pronunciation, the writer applied the following rubric as the standard of evaluation:

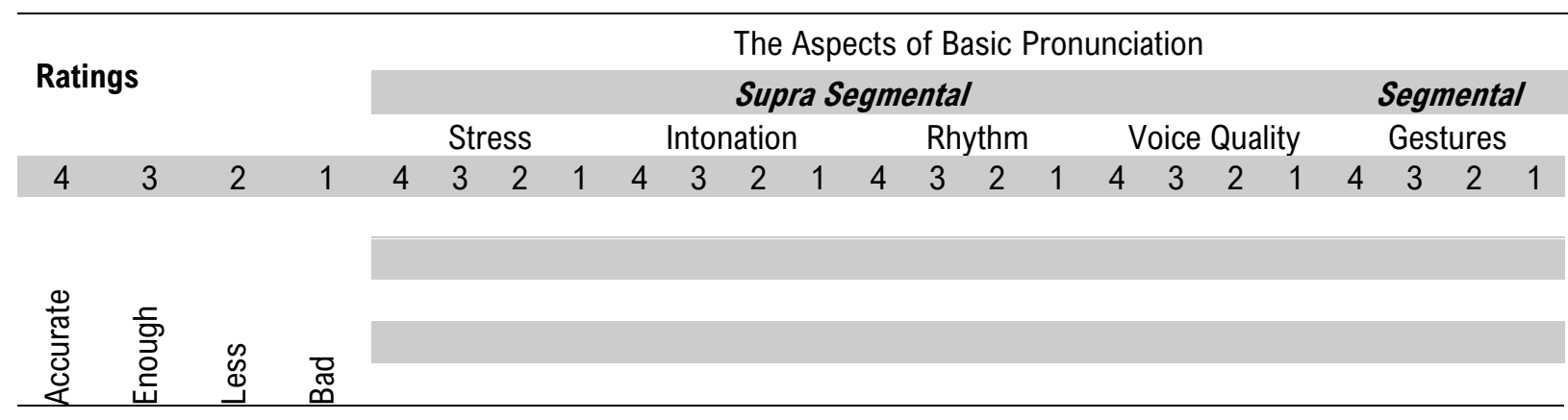

(Modified from: Sample Assessment Rubric http://www.p12.nysed.gov/ciai/lote/pub/lotecassess.pdf)

Note:

Rating score 4: Phonetically correct, almost error-free, Awareness of accent, and Genuine effort to sound like native speaker. (It is considered Accurate),

Rating score 3: Comprehensible, Generally correct Occasional error. (It is considered Average),

Rating score 2: Frequent errors that confuse listener and require guessing at meaning. (It is considered Less),

Rating score 1: Many errors that interfere with comprehensibility, most utterances contain errors, many utterances are incomprehensible, and little communication. (It is considered bad).

The range of score started from $4-1$. The level of mastery categorized very good when the student got 4, 3 was Good, 2 was Average and 1 was Weak.

Base on the collected data of 26 respondents established as sample of this present study variable data of Basic Pronunciation tabulated. To measure the students' level of ability the writer applied the following formula: $\mathrm{S}=\mathrm{TS} / \mathrm{TA}$ (Note: $\mathrm{S}=\mathrm{Score}, \mathrm{TS}=$ Total of score, and TA= Total of aspect).

\section{Results}

There were 26 students joined the test. In the test, each student had to pronounce the Basic English words based on the two aspects of pronunciation such as Supra-segmental covered stress, intonation, rhythm, and voice quality, and the Segmental aspect of Pronunciation is Gestures. The time allocation was 90 minutes. The results of data analysis are presented in the following table: 


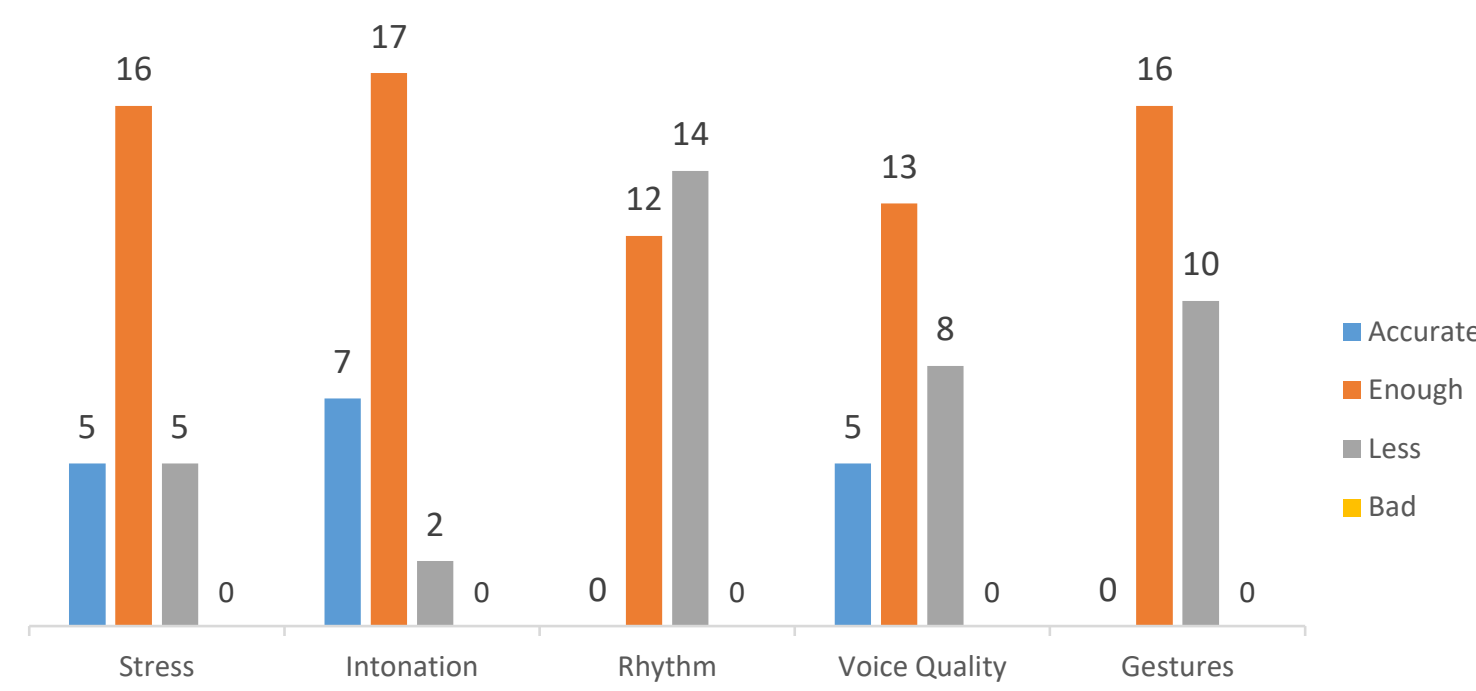

Graph 1. The mastery of the students' ability towards basic English pronunciation

Graph 1 depicted that the students mostly had the 'Enough' level of ability at the four elements of supra-segmental as such: stress, intonation, voice quality and gesture. Specifically, at this 'Enough level', there were 16 students (61.5\%) of 'Stress' element, 17 students $(65.3 \%)$ of 'Intonation' element, 13 students (50.0\%) of 'Voice Quality' and 'Gestures' as part of Segmental element was 16 students (61.5\%). Meanwhile, at the 'Rhythm' element, most students $(53.8 \%=14$ students) showed the 'Less' ability in this element and only $12(46.1 \%)$ categorized at the level of 'enough". Otherwise, there were no students in the 'Bad' level category.

Graph 2 showed that based on the students mastery level of basic English pronunciation, most students have the ability level of "Good" at the four elements such as stress, intonation, voice quality and intonation.

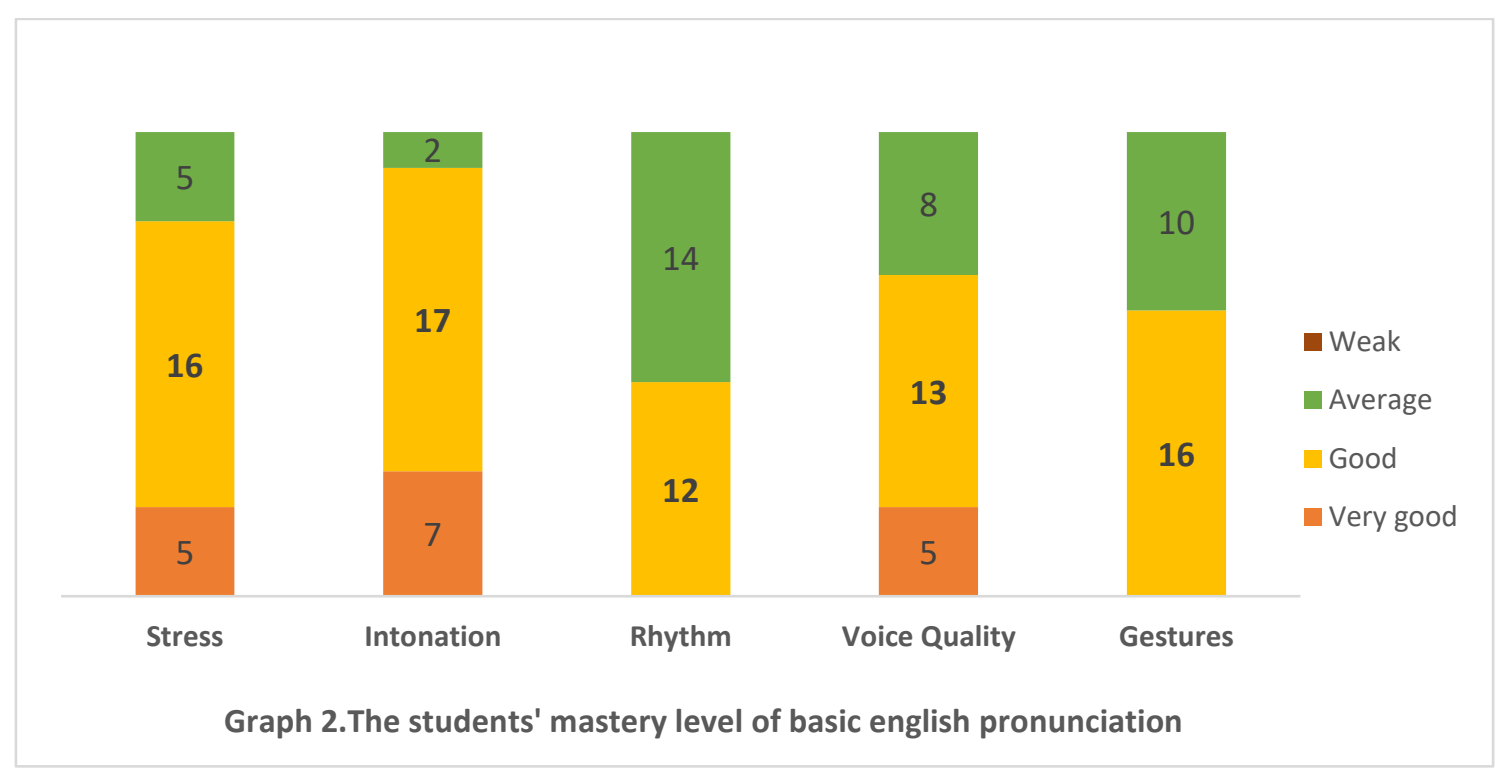




\section{Discussion}

\section{The Students' Mastery of Basic English Pronunciation}

Students were categorized mastered "enough"' on Basic English Pronunciation which proved by their ability in speaking performance, however, partly the students had not mastered in "voice quality" element of supra-segmental aspect and "gestures" element of segmental aspect. Even though the students were categorized at the 'good level', few students still found it difficult to pronounce certain words in both aspects of English Pronunciation which explained at the following discussion.

\section{The Students' Difficulties of Basic English Pronunciation}

In this study, students got difficulties in 'stress' and 'rhythm' elements of Basic English Pronunciation (BEP). Firstly, for the consonant sound of [f] in words: "philosophy", they should pronounce it /ft'IDsəfi/ yet many students pronounced it /pilosophi/. Further, the consonant sound of [3], for example in words: "measure" for /'mعzə/, "genre" for /ZHänrə/, "version" for /vərZHən/, garage for /ga'räZH/, however, still some students pronounced it "measur, genre, fersen, and geres". Moreover, the consonant sound of [J] in words: 'shy' became 'sai' instead of /SHī/, 'shot' for /SHät/ sounded 'sot', and 'bush' for /boðSH/ be like 'bus'. Last part was for the consonant sound of [r] "written", many students pronounce it as "wraiten" "but it should be pronounced as "/'ritn/". Here the students were able to pronounce those mentioned words above, nevertheless, they actually did not know the exact or the correct pronunciation where and when they have to stress on certain words with their rhythms. A similar discovery was also stated in Habibi's (2016), Luviya's (2016) and Anindita's (2017) where $/ \mathrm{V} /,|\theta /, / \delta /,| \mathrm{z} /, / \mathrm{J} /$ were mispronounced happened some times. Furthermore, this finding also correlates with the finding from Algifari (2017) who also found word stress mispronunciations in two-syllable, three-syllable, and four syllable words.

Following this, the "voice quality" of the students were at level of 'enough' category. It meant that there were still few students had difficulties on articulating the words. They were not paying attention on their voice when pronouncing the basic words. With a slow, deep, and low voices, it could show that they were doubtful in uttering those particular words.

The "intonation" of the students in pronouncing Basic English words was 'enough' category. However, there were still many students did not know how to produce intonation in pronouncing a word, thus, they made many mistakes. For example for the consonant sound of [ $\left.\mathrm{k}^{\mathrm{h}}\right]$, [k] for the words: "character", as /'karəktə/ but many students pronounced it as "ca.rakter" and the word, "cheek" /CHēk/ as few students uttered it 'cek' and others pronounced it 'sik'. Therefore, Intonation is a significant feature in English. The purpose of intonation, according to Gilbert (2008), is "helping the listener to follow."

Last but not least, "gesture" is a crucial part when one is speaking. It is also needed to use gestures to clarify the meaning revealed. In the contrary, some students still did not give their gestures when they were pronouncing the English words. They seemed to be shy and nervous or afraid when they articulate the words. 


\section{The Level Mastery of Students of Basic English Pronunciation}

Based on the data analysis, the students' level of mastery on the Basic English pronunciation was 'good', however there were some parts in both aspects of Supra-segmental and segmental in stress, intonation, rhythm, voice quality and gesture need to be improved.

\section{Conclusion}

Based on the data analysis and the discussion above, it can be concluded that the students were categorized 'average' level in mastering the Basic English Pronunciation (BEP). This proof that their ability in speaking performance still find difficulties. Nevertheless, students partly not mastered in 'voice quality' element yet in Supra segmental aspect and 'gestures' element in segmental aspect. It can be seen in the data analysis that the students mostly had the 'Enough' level of ability at the four elements of supra-segmental as such: stress, intonation, voice quality and gesture. Specifically, at this 'Enough level', there were 16 students $(61.5 \%)$ of 'Stress' element, 17 students (65.3\%) of 'Intonation' element, 13 students $(50.0 \%)$ of 'Voice Quality' and 'Gestures' as part of Segmental element was 16 students $(61.5 \%)$. Meanwhile, at the 'Rhythm' element, most students $(53.8 \%=14$ students $)$ showed the 'Less' ability in this element and only $12(46.1 \%)$ categorized at the level of 'enough". Otherwise, there were no students in the 'Bad' level category. However, few students still encountered difficulties in Segmental element (Voice Quality) and Supra-segmental parts such as words' stressing, intonation, rhythm, and gestures respectively.

From the conclusion, the writer would like to give suggestions to English students, teachers, and further researchers. Firstly for the students to practice more English pronunciation not only in the classroom lessons, however, there are too many ways on improving English pronunciation, such as by watching movies or watching English tutorials from the YouTube channels then apply those words to practice speaking with your friends. Next is for the English Teachers to employ more methods in teaching pronunciation besides drilling in the classrooms. Moreover, teachers should familiarize their learners to both American and British English and learners should be able to understand both varieties of pronunciation and EFL teachers should speak clearly and slowly in their pronunciation classes and they should convince their learners that their language is understandable. They are providing meaningful materials, using songs, games and tongue twisters and assessing students' progress. Eventually, for the further researchers to focus more on the aspect of Rhythm and gestures beside the four elements of supra-segmental aspect especially on the 'stressing' words.

\section{Acknowledgment}

This study was a self-classroom research at the ESP, Faculty of Educational Sciences, State University of Timor (UNIMOR), Indonesia in January 2019. The first and foremost, the writer would like to express her deepest gratitude to God Almighty for His blessing, grace, and guidance in accomplishing this research writing. Her deepest gratitude goes also to her colleague, Ms. Manti, who has contributed her time, helps, discussions, and feedback in finishing this writing. Special thanks are eventually addresses to the writer's ESP freshmen students for their participation as the subject of the research. 


\section{References}

Anindita, L. (2017). English mispronunciation produced by radio Masdha announcers. Undergraduate Thesis. Yogyakarta: Sananta Dharma University.

Algifari, M. Y. (2017). Analyzing students' pronunciation of word wtress of IET 7 students of Cambridge English College (CEC) Makassar. Undergraduate Thesis. Makassar: Alauddin State Islamic University of Makassar.

Gilakjani, A. P. (2016). English Pronunciation Instruction: A Literature Review. Retrieved from http://ijreeonline.com/article-1-21-en.pdf

Gilbert, J. B. (2008). Teaching Pronunciation Using the Prosody Pyramid. Cambridge University Press.

Habibi, M. W. (2016). English pronunciation problems encountered by Indonesian advanced students. Undergraduate Thesis. Malang: Maulana Malik Ibrahim State Islamic University of Malang.

Hassan, E. M. I. (2014). Pronunciation problems: A case study of English language students at Sudan University of Science and Technology. English Language and Literature Studies, 4(4), 31-44. https://doi.org/10.5539/ells.v4n4p31

Hewings, M. (2004). Pronunciation practice activities: A resource book for teaching English pronunciation. Cambridge, UK: Cambridge University Press.

Kelly, G. (2000). How to teach pronunciation. Harlow, UK: Pearson Education Limited.

Kenworthy, J. (1987). Teaching English pronunciation. New York, NY: Longman.

O'Connor, J. D. (2009). Better English Pronunciation. London: Cambridge University Press.

Luviya, S. (2016). Mispronunciation of some English consonants by Javanese students in English literature of Sanata Dharma University. Undergraduate Thesis. Yogyakarta: Sanata Dharma University.

Roach, P. (2009). English Phonetics and Phonology 4th edition. Cambridge. Cambridge University Press. Retrieved from https://www.academia.edu/34074049/Peter_Roach_English_Phonetics_and_Phonology 4th_edition_Cambridge_

Underhill, A. (2005). Sound foundations: Learning and teaching pronunciation ( $2^{\text {nd }}$ ed.). Oxford, UK: Macmillan Publishers.

Walliman, N. (2005). Your Research Project, $2^{\text {nd }}$ edition. London. Thousand Oaks. New Delhi: Sage Publications.

Yates, L. (2002). What is pronunciation? Retrieved from:

http://www.ameprc.mq.edu.au/docs/fact_sheets/01Pronunciation.pdf 